\title{
Effect of 21 August 2017 solar eclipse on surface-level irradiance and ambient temperature
}

\author{
David M. Calamas $^{1}$ (D) $\cdot$ Christopher Nutter ${ }^{1} \cdot$ Dianna Nicole Guajardo $^{1}$
}

Received: 6 July 2018 / Accepted: 7 November 2018 / Published online: 15 November 2018

(c) The Author(s) 2018

\begin{abstract}
The temporal variation in the direct normal irradiance, diffuse horizontal irradiance, global horizontal irradiance, and ambient temperature was quantified during the 21 August 2017 solar eclipse. The magnitude and obscuration of the eclipse at the observation location were 0.97 and $96.94 \%$, respectively. A two-axis sun tracker equipped with a pyrheliometer, a shaded pyranometer, an unshaded pyranometer, and a pyrgeometer were utilized to obtain the solar irradiance measurements. Thermistors contained within the pyrheliometer and the pyrgeometer were used to quantify changes in temperature. Unfortunately, on the day of the eclipse, the weather conditions were not ideal and periodic cloud coverage impacted measurements of the direct normal irradiance. As such, solar irradiance and temperature data from 2 days prior, when the weather conditions were near-ideal, are presented for comparison. The temperature of the air as measured by the thermistors enclosed within the pyrheliometer and pyrgeometer recorded an average temperature drop of $8.49{ }^{\circ} \mathrm{C}$. The minimum temperature was recorded approximately $47 \mathrm{~min}$ after totality. The diffuse horizontal irradiance reached a maximum value of $495.9 \mathrm{~W} / \mathrm{m}^{2}$ shortly after the start of partial eclipse and dropped to a minimum value of $0 \mathrm{~W} / \mathrm{m}^{2}$ near totality. Similarly, the global horizontal irradiance reached a maximum value of $1138 \mathrm{~W} / \mathrm{m}^{2}$ and dropped to a minimum value of $1.54 \mathrm{~W} / \mathrm{m}^{2}$ near totality. For reference, at the same time of day, but 2 days prior, the diffuse horizontal irradiance and global horizontal irradiance were at values of $89.2 \mathrm{~W} / \mathrm{m}^{2}$ and $962 \mathrm{~W} / \mathrm{m}^{2}$, respectively, under clear sky conditions. The rate of decrease in the temperature of the air as well as in the diffuse and global horizontal irradiances after first contact and before totality was greater than the rate of increase in these parameters after totality. The difference in the magnitude of these gradients before and after totality is largely attributed to normal diurnal variations as the solar eclipse occurred in the afternoon.
\end{abstract}

Keywords Solar irradiance $\cdot$ Solar eclipse $\cdot$ Total eclipse $\cdot$ Temperature

\section{Introduction}

A total solar eclipse provides a unique opportunity to study temporal changes in the direct and diffuse components of solar irradiance at the surface not associated with normal diurnal variations. In addition to changes in the magnitude of the solar irradiance, the occultation of the sun by the moon also impacts various meteorological variables such

David M. Calamas

dcalamas@georgiasouthern.edu

Christopher Nutter

cn01235@georgiasouthern.edu

Dianna Nicole Guajardo

dg03162@georgiasouthern.edu

1 Department of Mechanical Engineering, Georgia Southern University, P.O. Box 8046, Statesboro, GA 30460, USA as temperature, wind speed, and relative humidity. The solar eclipse on 21 August 2017 in the United States afforded researchers the opportunity to collect measurements in the path of totality. The path of totality crossed the United States from the Northwest to the Southeast. The first point of contact was near Lincoln Beach, Oregon at 16:05 UT and the last point of contact was near Charleston, South Carolina at 20:09 UT. The longest duration of totality, $2 \mathrm{~min}$ and $40.2 \mathrm{~s}$, occurred near Carbondale, Illinois at 16:52 UT.

The authors in this study observed the solar eclipse from Statesboro, Georgia (Latitude: $32.4205^{\circ} \mathrm{N}$, Longitude: $81.7865^{\circ} \mathrm{W}$, elevation: $77 \mathrm{~m}$ ) at Georgia Southern University. The magnitude and obscuration of the eclipse at this location were 0.97 and $96.94 \%$, respectively. The start of partial eclipse, or first contact, occurred at 17:13:10.3 UT where the sun was located at an altitude and azimuth of $69.1^{\circ}$ and $168.3^{\circ}$, respectively. Maximum eclipse occurred at 
18:44:06.5 UT where the sun was located at an altitude and azimuth of $63.3^{\circ}$ and $223.8^{\circ}$, respectively. Finally, the end of partial eclipse, or fourth contact, occurred at 20:08:03.6 UT where the sun was located at an altitude and azimuth of $48.4^{\circ}$ and $249.6^{\circ}$, respectively. The path of totality, in relation to the state of Georgia and the observation location, can be seen in Fig. 1. Of interest to the authors was the temporal variation of the direct normal irradiance, diffuse horizontal irradiance, global horizontal irradiance, and ambient temperature during the eclipse. An overview of these measurements in a historical context can be found below.

\section{Historical solar irradiance observations}

Fernandez et al. [1] investigated changes in solar irradiance and atmospheric turbidity during the 11 July 1991 solar eclipse. Fernandez et al. measured both the global solar irradiance and the spectral solar irradiance-largely within the visible light and ultraviolet spectrums. In their analysis, Fernandez et al. adopted the divisions of the solar spectrum in various color bands as recommended by the World Radiation Center (WRC) and presented by Iqbal [2]. The authors found that there was not a more significant contribution by any specific wavelength band (i.e., color) within the visible spectrum and each color band followed, qualitatively, the same trend during the solar eclipse. Later, Fernandez et al. [3] observed changes in global solar irradiance, air temperature, relative humidity, and wind speed during the 3 November 1994 solar eclipse. Of interest in this analysis is the authors' measurements of solar irradiance

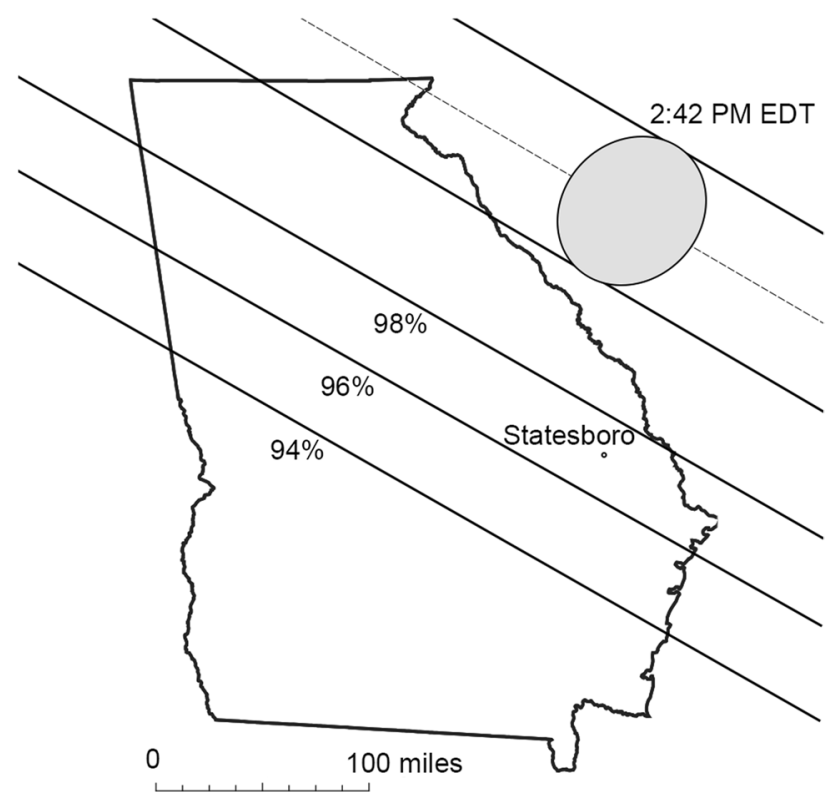

Fig. 1 Path of totality and observation location in Statesboro, Georgia, United States and air temperature. The global solar irradiance decreased after first contact and reached a minimum at totality. After fourth contact, and because the solar eclipse occurred in the morning, the solar irradiance resumed following a normal diurnal trend.

While some researchers have chosen to focus on the total solar irradiance, others have focused their efforts on spectral, or wavelength-dependent solar irradiance. Of particular interest is solar irradiance in the ultraviolet (UV) spectrum due to the impact that exposure to UV radiation has on biological organisms. For example, Zerefos et al. [4] investigated changes in solar irradiance in the ultraviolet spectrum during the 11 August 1999 solar eclipse. The authors found that the distribution of solar irradiance in the ultraviolet spectrum was wavelength dependent. Within the UV spectrum, the solar irradiance at shorter wavelengths was found to decrease by a greater amount than solar irradiance at longer wavelengths. In addition, the authors found that the direct component of the solar irradiance decreased by a more significant amount than the diffuse component during the solar eclipse. The decrease in the direct component of the solar irradiance is directly proportional to the obscuration of the solar disk. However, when considering the diffuse component, one must consider that the solar irradiance measured could have originated from regions of the sky under different eclipse conditions due to scattering in the atmosphere.

Several researchers have sought to quantify the impact of limb darkening on the spectral distribution of solar irradiance. The phenomenon of limb darkening is exhibited by a gradual decrease in the brightness of the solar disk as observed from its center to its edge (or limb). This phenomenon occurs because the solar atmosphere increases in temperature with depth. In addition, the visible light near the edge of the solar disk must traverse through a greater length of the photosphere (the visible surface of the sun) than visible light emanating from near the center of the disk. Therefore, the relative contribution of radiation emanating from the center and the limb varies during an eclipse. The emission characteristics are also dependent on wavelength due to the varying temperatures within the photosphere (from $4400 \mathrm{~K}$ at the top of the photosphere to $6600 \mathrm{~K}$ at the bottom). Thus, during an eclipse, the extraterrestrial solar irradiance is both spectral (wavelength dependent) and temporal (time dependent).

Blumthaler et al. [5] quantified the spectral distribution of solar irradiance in the UV spectrum and subsequent changes in the total ozone column based on the measurements taken during the 29 March 2006 solar eclipse. The authors' measurements indicated a decrease in the total ozone column before totality followed by a symmetric increase after totality. Blumthaler et al. found that the limb darkening phenomenon had an insignificant impact on changes to the total ozone column. Instead, the authors attributed the measured 
reduction in the total ozone column to contamination of direct normal irradiance measurements by diffuse components. In good agreement with Zerefos et al. [4], the authors found that the attenuation of solar irradiance during the eclipse was not purely a function of the geometrical sun coverage but was also wavelength dependent. More specifically, the authors found that the solar irradiance at shorter wavelengths was reduced by a greater amount during the eclipse than solar irradiance at longer wavelengths. It should be noted that a consortium of researchers participated in the quantification of surface and extraterrestrial solar irradiance during the 29 March 2006 solar eclipse from the same location and similar conclusions can be found in the manuscripts of Kazadzis et al. [6] and Kazantzidis et al. [7].

\section{Historical atmospheric temperature observations}

Phillips [8] developed a semi-theoretical model for predicting air temperature fluctuations as a function of time during a solar eclipse. In his model, Phillips assumed that the intensity of the solar radiation was constant. Thus, absorption of the solar irradiance in the atmosphere and the optical depth of the atmosphere were neglected. In addition, scattering of solar radiation in the atmosphere was neglected. Despite the aforementioned limitations, Philips' model was in good agreement with experimental measurements taken during the solar eclipse on 20 May 1966. Phillips noted that the occultation of the sun by the moon would affect the diurnal variation of the air temperature. However, a temperature drop need not necessarily occur. In fact, while a small temperature drop was experimentally measured, Phillips' model did not predict a temperature drop. This is because the solar eclipse occurred in the morning at the author's location. As such, the rate of change in the air temperature was predicted to decrease until the time of maximum eclipse after which the temperature would increase again. To reiterate, the author pointed out that a decrease in the magnitude of the air temperature is not a physical requirement. Instead, only a decrease in the magnitude of the temperature gradient is mandated during a morning eclipse. However, in the literature reviewed in the present study, temperature drops were in fact recorded in all instances.

Fernandez et al. investigated changes in air temperature and wind speed during the 11 July 1991 solar eclipse [9]. Fernandez et al. reported temporal changes in the temperature of the air at multiple locations. In good agreement with Anderson [10], the smallest temperature drop recorded was between 2.0 and $2.5^{\circ} \mathrm{C}$ while the largest was $8.5^{\circ} \mathrm{C}$. In addition, the minimum temperatures were reached between 10 and $30 \mathrm{~min}$ after totality, depending on the locality. Three years later, during the 3 November 1994 solar eclipse, Fernandez et al. [3] measured a $3{ }^{\circ} \mathrm{C}$ drop in the temperature of the air. The minimum temperature was recorded approximately $7 \mathrm{~min}$ after totality. The rate of temperature decrease between the start of partial eclipse and maximum eclipse was greater than the rate of temperature increase between maximum eclipse and the end of partial eclipse. This behavior was attributed to the solar eclipse occurring in the morning.

Anderson [10] reviewed the meteorological changes associated with solar eclipses in advance of the 11 August 1999 solar eclipse. Anderson addressed the shortcomings of historical measurements of atmospheric conditions during solar eclipses and indicated areas in which more comprehensive data collection was required. Anderson surveyed eight studies that analyzed the temporal change in the temperature of the atmosphere near the surface and found that there was an average decrease in temperature of approximately $4{ }^{\circ} \mathrm{C}$. The average minimum temperature was found to occur approximately $11 \mathrm{~min}$, on average, after the point of maximum eclipse. The measurements were taken at an average of $4 \mathrm{~m}$ above ground level. Peñaloza-Murillo and Pasachoff [11] developed a semi-empirical mathematical model of the temporal change in the temperature of the air during a total solar eclipse. Their mathematical model was able to accurately predict the time delay between the minimum solar irradiance, which occurs at totality, and the minimum ambient temperature. In a supplementary material document accompanied with their manuscript, the authors also provided a comprehensive list of publications, organized chronologically, which focused on temperature observations during solar eclipses.

\section{Solar irradiance and atmospheric parameters quantified}

It should be noted that several researchers have quantified the spectral, or wavelength dependent, variations of irradiance during total solar eclipse conditions [12-14]. However, in the present analysis, the total solar irradiance will be quantified. Of particular interest is measurement of the direct normal irradiance, diffuse horizontal irradiance, global horizontal irradiance, and ambient temperature. This information is of particular interest because a total solar eclipse provides a unique opportunity for researchers to study the atmosphere's reaction to abrupt changes in irradiance. In addition, subsets of the data presented in this analysis could be used by researchers to assist in the quantification of aerosol optical depth and total column ozone $[4,15,16]$.

\section{Experimental methodology}

Of interest to the authors in this analysis was the quantification of the temporal variation of the direct and diffuse components of the solar irradiance under near-total solar eclipse 
conditions. The direct normal irradiance (DNI) was measured by a pyrheliometer (Kipp \& Zonen CHP1). The diffuse horizontal irradiance (DHI) was measured by a shaded pyranometer (Kipp \& Zonen CMP10) while the global horizontal irradiance (GHI) was measured by an unshaded pyranometer (Kipp \& Zonen CMP10). Long-wave atmospheric radiation was measured by a shaded pyrgeometer (Kipp \& Zonen CGR4). The aforementioned instruments were each equipped with ventilation units (Kipp \& Zonen CVF4) as necessatated by the temperature and humidity of the testing environment. The pyrheliometer, two pyranometers, and pyrgeometer were mounted on a two-axis sun tracker (Kipp $\&$ Zonen SOLYS 2). The sun tracker has a passive tracking accuracy of $0.1^{\circ}$. However, a sun sensor was equipped to correct for clock drift and possible movement of the support platform. The sun sensor, which utilizes active tracking, increased the tracking accuracy to $0.02^{\circ}$. The sun tracker and the attached instrumentation were located on a platform $10 \mathrm{~m}$ above ground level. The spectral range, sensitivity, response time, temperature dependence of sensitivity, nonlinearity, and field of view of the instruments can be found in Table 1. Please note that two sensitivities are listed for the pyranometers (Kipp \& Zonen CMP10). The first sensitivity is for the shaded pyranometer while the second sensitivity is for the unshaded pyranometer.

The pyrheliometer was calibrated by the manufacturer with a reference pyrheliometer that was calibrated at the World Radiation Centre (WRC) in Davos, Switzerland. The accuracy of the pyrheliometer calibration is $\pm 0.5 \%$. The CHP1 is classified as a first class pyrheliometer per ISO standard 9060:1990. The two pyranometers were calibrated by the manufacturer in accordance with the ISO standard 9847:1992. The CMP10 pyranometers are classified as secondary standard pyranometers per ISO standard 9060:1990. As with the pyrheliometer, the pyrgeometer was calibrated with a reference pyrgeometer that was calibrated at the WRC. The pyrheliometer and pyrgeometer contain $10 \mathrm{k} \Omega$ thermistors (YSI 44031) that have an accuracy of $\pm 0.1^{\circ} \mathrm{C}$.

The instruments were connected to a data logger (Campbell Scientific CR1000) that communicated via ethernet to

Table 1 Solar irradiance instrumentation specifications

\begin{tabular}{llll}
\hline Specification & CHP1 & CMP10 & CGR4 \\
\hline Spectral range $(\mathrm{nm})$ & $200-4000$ & $285-2800$ & $4500-42000$ \\
Sensitivity $\left(\mu \mathrm{V} / \mathrm{W} / \mathrm{m}^{2}\right)$ & 8.06 & $8.13,9.04$ & 11.56 \\
Response time $(\mathrm{s})$ & 5.0 & 5.0 & 18.0 \\
$\begin{array}{l}\text { Temperature dependence } \\
\quad 0 \text { sensitivity }(\%)\end{array}$ & 0.5 & 1.0 & 1.0 \\
$\quad$ Nonlinearity $(\%)$ & 0.2 & 0.2 & 1.0 \\
Spectral sensitivity $(\%)$ & 5.0 & 3.0 & 5.0 \\
Field of view $\left({ }^{\circ}\right)$ & $5.0 \pm 0.2$ & 180 & 180 \\
\hline
\end{tabular}

a remote desktop operating a data logger support software package (Campbell Scientific LoggerNet 4.5). Data from each of the instruments was acquired with a temporal resolution of $1 \mathrm{~s}$. However, average values, with a temporal resolution of $1 \mathrm{~min}$, are presented in figures for clarity. The solar irradiance and temperature data are presented from a time of $2 \mathrm{~h}$ before the start of partial eclipse, or first contact, to $2 \mathrm{~h}$ after the end of partial eclipse, or fourth contact.

\section{Results and discussion}

\section{Weather conditions}

Unfortunately, on the day of the total solar eclipse (21 August 2017), the weather conditions were not ideal. Cloud coverage, reported in oktas (or eighths), was recorded by the local climatological data station at the Statesboro-Bulloch County Airport (Airport Code: TBR, WBAN ID: 63818). The station data were accessed via the Climate Data Online (CDO) tool available at the National Centers for Environmental Information's (NCEI) website (the NCEI was formerly known as the National Climatic Data Center, or NCDC). While there was no precipitation, cloud coverage fluctuated between clear (1-2 oktas), scattered (3-4 oktas), and broken (5-7 oktas) throughout the observation window reported in this study. As such, and to quantify the impact of the eclipse on solar irradiance and ambient temperatures near the surface, data were also collected 2 days prior to the eclipse (19 August 2017). On this day, the meteorological conditions were near ideal with clear sky conditions reported throughout the observation window.

\section{Environmental temperature observations}

The temperatures reported were recorded by the thermistors enclosed within the pyrheliometer (Kipp \& Zonen CHP1) and the pyrgeometer (Kipp \& Zonen CGR4). As the thermistors were contained within the instruments' enclosures, they were not exposed to the environment directly. Therefore, it was expected that the magnitude of the temperatures recorded would be higher than that of the actual ambient temperature. However, the temperatures should follow a qualitatively similar trend to the actual environmental temperature. In any case, the actual magnitude of the temperature is less significant than the change in temperature during the duration of the eclipse. The temperatures recorded by the thermistors enclosed within the pyrheliometer (CHP1) and pyrgeometer (CGR4) as well as the temperatures as recorded by the local climatological data station (TBR) 2 days prior to the eclipse can be seen in Fig. 2. As an example, the temperatures recorded by the enclosed thermistors 2 days prior to the eclipse follow a qualitatively similar trend as 


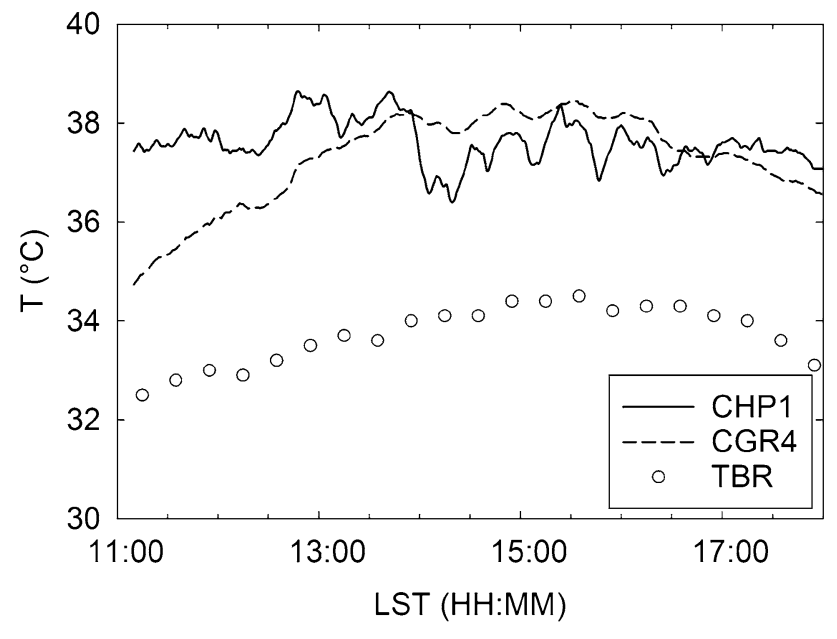

Fig. 2 Ambient temperature as a function of time on 19 August 2017

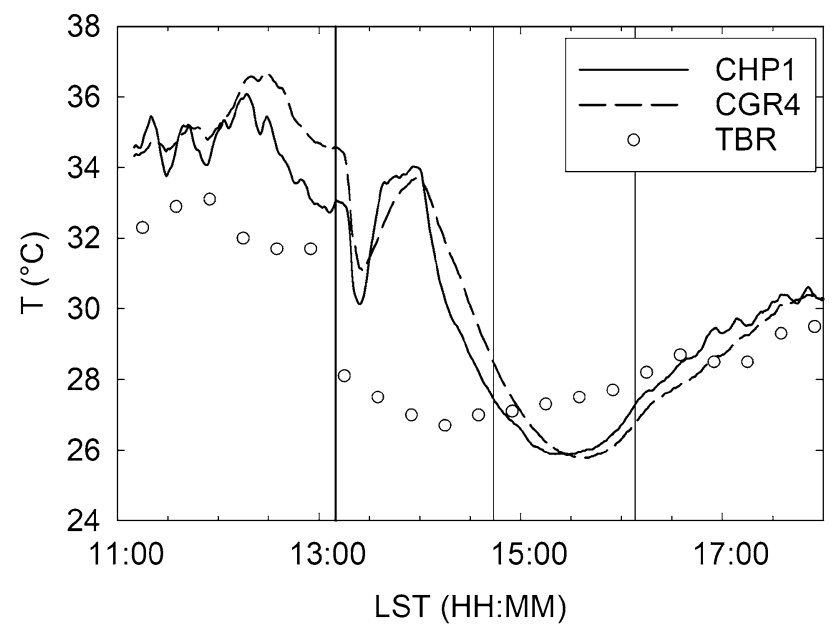

Fig. 3 Ambient temperature as a function of time on 21 August 17

the ambient temperature recorded by the local climatological data station. However, the temperatures recorded by the enclosed thermistors were, on average, $3.7{ }^{\circ} \mathrm{C}$ higher than those recorded by the local climatological data station (TBR).

The temperatures recorded by the thermistors enclosed within the pyrheliometer (CHP1) and pyrgeometer (CGR4) as well as the temperatures as recorded by the local climatological data station (TBR) on the day of the eclipse (21 August 2017) can be seen in Fig. 3. The vertical lines in the figure correspond to the start of partial eclipse, maximum eclipse, and the end of partial eclipse. The start of partial eclipse occurred at 13:13:10.3 LST and the end of partial eclipse occurred at 16:08:03.6 LST. During this time frame, the maximum temperature recorded by the pyrheliometer and pyrgeometer was $34.03{ }^{\circ} \mathrm{C}$ and $34.59{ }^{\circ} \mathrm{C}$, respectively. In the same time frame, the minimum temperature recorded by the pyrheliometer and pyrgeometer was $25.86{ }^{\circ} \mathrm{C}$ and $25.79^{\circ} \mathrm{C}$, respectively. The difference between the maximum and minimum temperatures as measured by the pyrheliometer and pyrgeometer was $8.17^{\circ} \mathrm{C}$ and $8.80^{\circ} \mathrm{C}$, respectively. The average temperature drop during this time frame was $8.49^{\circ} \mathrm{C}$. The temperature drop recorded by the local climatological data station was $5.0^{\circ} \mathrm{C}$. It should be noted, however, that the local climatological data station is located $8.73 \mathrm{~km}$ $(5.42 \mathrm{mi})$ from the location of the solar irradiance instrumentation utilized by the author.

Totality occurred at 14:44:06.5 LST. The lowest temperature measured by the pyrheliometer occurred at 15:28:00 LST while the lowest temperature measured by the pyrgeometer occurred at 15:34:00 LST. Thus, the minimum temperature recorded by the pyrheliometer occurred approximately $43 \mathrm{~min}$ and $53.5 \mathrm{~s}$ after totality. Similarly, the minimum temperature recorded by the pyrgeometer occurred approximately $50 \mathrm{~min}$ and $53.5 \mathrm{~s}$ after totality.

While the magnitude of the drop in temperature is in good agreement with the literature, the time delay between the time of maximum eclipse and the time at which the minimum temperature was recorded was not. For example, in the data set utilized by Peñaloza-Murillo and Pasachoff, the minimum ambient temperature was recorded $8 \mathrm{~min}$ and $15 \mathrm{~s}$ after totality and remained constant for $9 \mathrm{~min}$ and $45 \mathrm{~s}$ (the lowest temperature was thus measured at a median time of approximately $13 \mathrm{~min}$ and $7 \mathrm{~s}$ after totality). A $7.34{ }^{\circ} \mathrm{C}$ drop in the temperature was observed between the start and end of the partial eclipse. The delay in the minimum temperatures recorded in this study can mainly be attributed to the location of the thermistors. As previously mentioned, the thermistors were enclosed and were not exposed to the environment directly. In addition, the eclipse occurred in the afternoon and, thus, normal diurnal temperature variation should be considered (sunset occurred at 19:05 LST on 21 August 2017).

\section{Rate of decrease in temperature before minimum temperature occurrence}

As previously stated, the temperature drop recorded in this analysis (an average of $8.49^{\circ} \mathrm{C}$ ) was of a similar magnitude to the temperature drop reported by Peñaloza-Murillo and Pasachoff $\left(7.34^{\circ} \mathrm{C}\right)$. It should also be noted that the data the authors utilized were also for an afternoon eclipse. As such, the temperatures follow a qualitatively similar trend. The temperature variation during the 21 June 2001 solar eclipse in Lusaka, Zambia can be seen in Fig. 4.

In the data set utilized by Peñaloza-Murillo and Pasachoff, the highest temperature recorded between first contact (the start of partial eclipse) and second contact (the start of total eclipse) was $27.12^{\circ} \mathrm{C}$. The lowest temperature recorded after third contact (the end of total eclipse) 


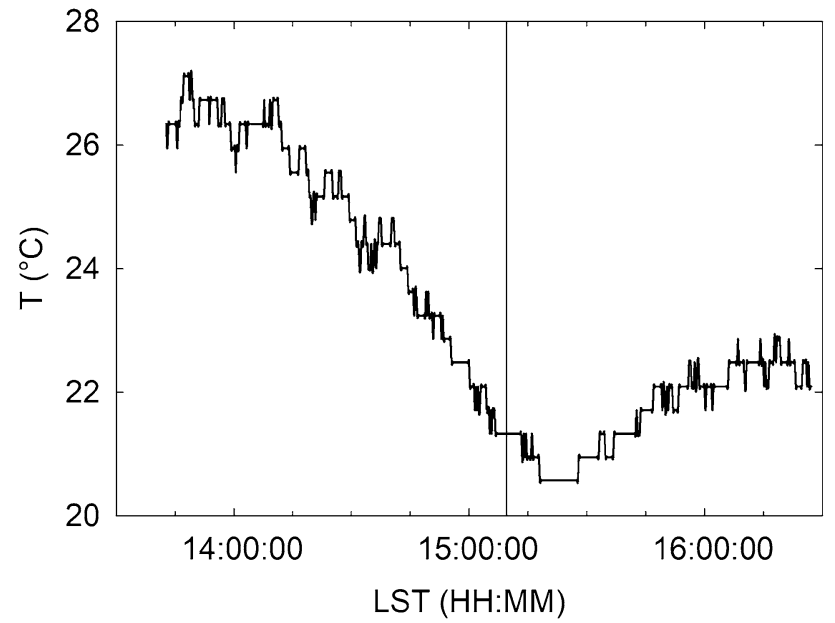

Fig. 4 Air temperature variation during the total occultation of the sun on 21 June 2001 [11]

was $20.57{ }^{\circ} \mathrm{C}$. The time between the highest and lowest recorded temperatures was approximately $91 \mathrm{~min}$. The temperature thus dropped at a rate of $0.072{ }^{\circ} \mathrm{C} / \mathrm{min}$. In the present analysis, the highest temperatures recorded by the pyranometer and pyrheliometer between first contact and second contact were $34.03{ }^{\circ} \mathrm{C}$ and $34.59^{\circ} \mathrm{C}$, respectively. The lowest temperatures recorded by the pyranometer and pyrheliometer were $25.86^{\circ} \mathrm{C}$ and $25.79{ }^{\circ} \mathrm{C}$, respectively. The time between the highest and lowest temperatures recorded by the pyranometer and pyrheliometer was 92 and $94 \mathrm{~min}$, respectively. Therefore, the temperature dropped at an average rate of $0.091{ }^{\circ} \mathrm{C} / \mathrm{min}$, in good agreement with Peñaloza-Murillo and Pasachoff.

\section{Rate of increase in temperature after minimum temperature occurrence}

In the data set utilized by Peñaloza-Murillo and Pasachoff, the highest temperature recorded between third contact (the end of total eclipse) and fourth contact (the end of partial eclipse) was $22.86{ }^{\circ} \mathrm{C}$. The time between the highest and lowest temperatures in this time frame was approximately $50 \mathrm{~min}$, and the temperature rose at a rate of $0.023{ }^{\circ} \mathrm{C} / \mathrm{min}$. In the present analysis, the highest temperatures recorded by the pyranometer and pyrheliometer between third and fourth contact were $27.28{ }^{\circ} \mathrm{C}$ and $26.74{ }^{\circ} \mathrm{C}$, respectively. The time between the highest and lowest temperatures recorded by the pyranometer and pyrheliometer during this time interval was 40 and 34 min, respectively. Thus, the temperature rose at an average rate of $0.032{ }^{\circ} \mathrm{C} / \mathrm{min}$.

\section{Solar irradiance observations}

To qualitatively describe, and quantitatively evaluate, the impact of the solar eclipse on solar irradiance the direct normal irradiance, diffuse horizontal irradiance, and global horizontal irradiance were measured 2 days prior to the eclipse (19 August 2017). As stated earlier, on this day the meteorological conditions were near-ideal with a predominately clear sky throughout the observation window.

\section{Direct normal irradiance}

The direct normal irradiance (DNI) was measured by a pyrheliometer (Kipp \& Zonen CHP1). The direct normal irradiance 2 days prior to the eclipse (19 August 2017) and on the day of the eclipse (21 August 2017) can be seen in Figs. 5 and 6, respectively. Two days prior to the eclipse,

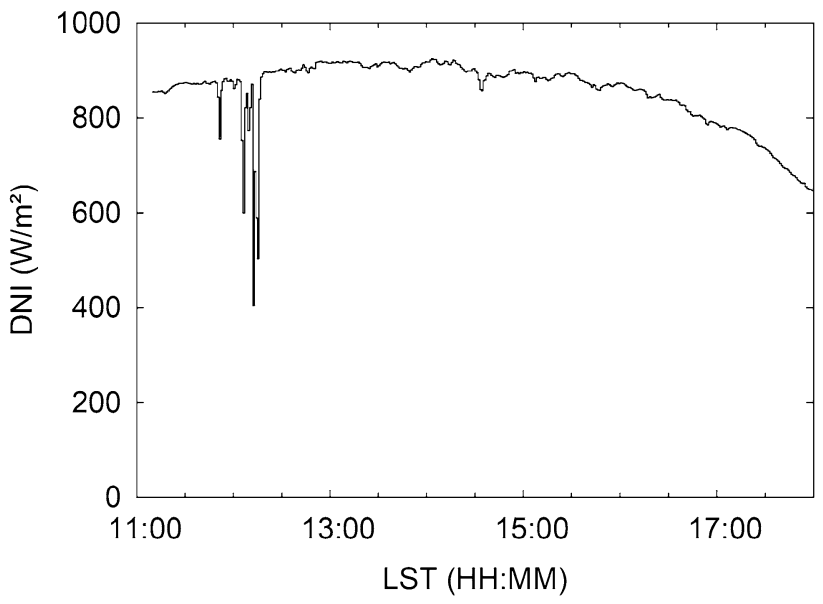

Fig. 5 Direct normal irradiance as a function of time on 19 August 2017

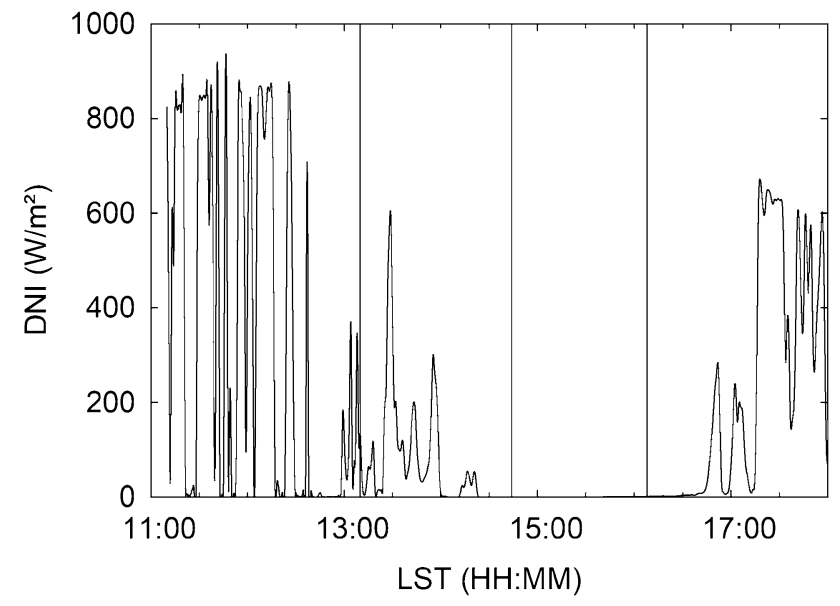

Fig. 6 Direct normal irradiance as a function of time on 21 August 2017 
the direct normal irradiance followed a traditional diurnal trend. A brief drop in the DNI, attributed to a brief presence of cloud coverage, can be seen between approximately 12:05 LST and 12:15 LST in Fig. 5. The DNI reached a maximum value of $925 \mathrm{~W} / \mathrm{m}^{2}$ at 14:04 LST. The maximum value was measured $37 \mathrm{~min}$ after solar noon which occurred at 13:27 LST. Unfortunately, on the day of the eclipse cloud coverage throughout the observation window impacted the ability to ascertain any qualitative trends from Fig. 6 . The three vertical lines in the figure correspond to the start of partial eclipse, maximum eclipse, and end of partial eclipse. On the day of the eclipse, the DNI reached a maximum of $869 \mathrm{~W} /$ $\mathrm{m}^{2}$ at 12:08 LST. In general, the DNI decreased after the start of partial eclipse and reached a value of $0 \mathrm{~W} / \mathrm{m}^{2}$ near totality. However, the increase in the DNI after totality and before the end of partial eclipse cannot be ascertained from this dataset due to the presence of cloud coverage.

\section{Diffuse horizontal irradiance}

The diffuse horizontal irradiance (DHI) was measured by a shaded pyranometer (Kipp and Zonen CMP10). The diffuse horizontal irradiance 2 days before the eclipse (19 August 2017) and on the day of the eclipse (21 August 2017) can be seen in Figs. 7 and 8, respectively. The reader should note that the same scaling is utilized on the axes of the figures for ease of comparison. The increase in the DHI between approximately 12:05 LST and 12:15 LST in Fig. 7 corresponds directly to the decrease in the DNI in Fig. 5. The brief increase in the DHI during this period is attributed to the scattering of the solar irradiance in the atmosphere due to transitory cloud coverage. The DHI had an average value of $81.1 \mathrm{~W} / \mathrm{m}^{2}$ during the observation window 2 days prior to the eclipse. On the day of the eclipse, the DHI reached

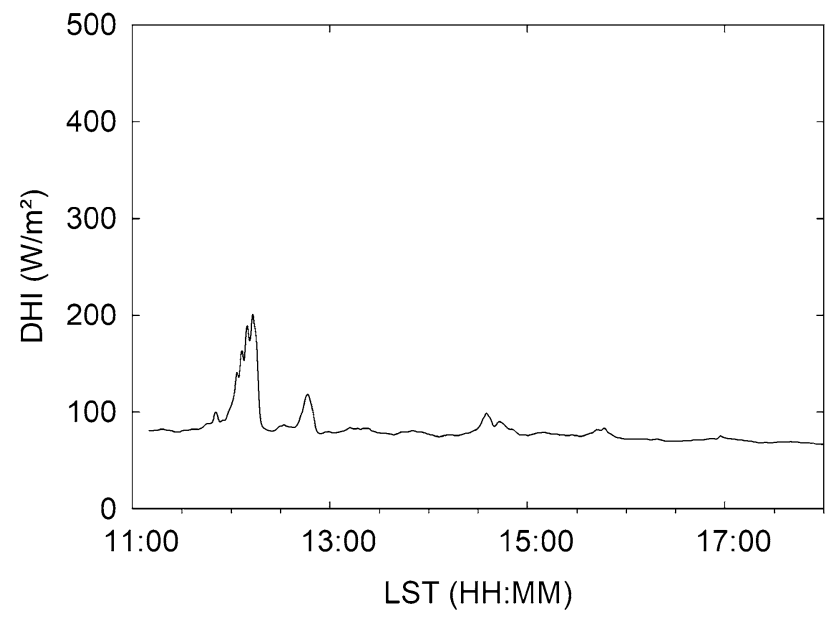

Fig. 7 Diffuse horizontal irradiance as a function of time on 19 August 2017

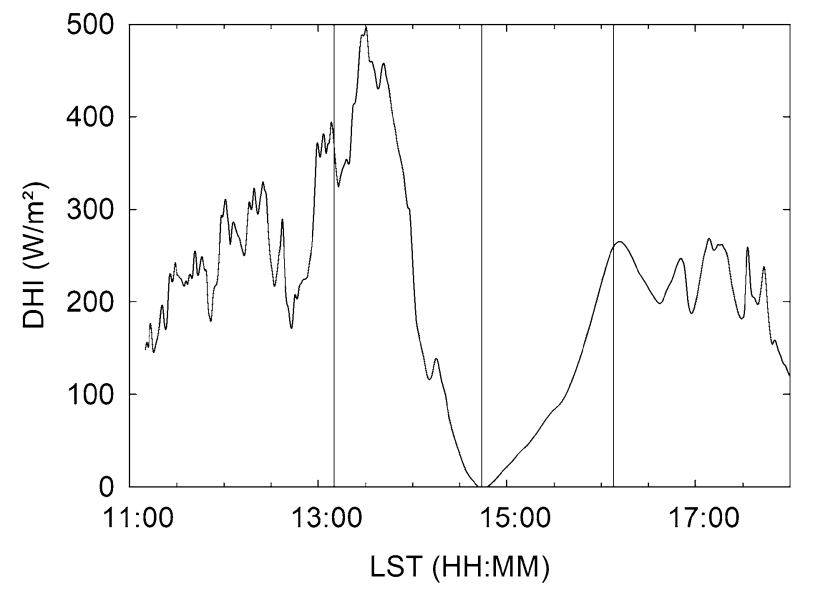

Fig. 8 Diffuse horizontal irradiance as a function of time on 21 August 2017

a maximum value of $495.9 \mathrm{~W} / \mathrm{m}^{2}$ at 13:30 LST, or $3 \mathrm{~min}$ after solar noon. This maximum was reached approximately 17 min after the start of partial eclipse which occurred at 13:13 LST. The DHI reached a minimum value of $0 \mathrm{~W} /$ $\mathrm{m}^{2}$ at 14:42 LST ( 2 min prior to totality) and remained at this value until 14:47 LST ( 3 min after totality). Thus, the diffuse horizontal irradiance reached a minimum value of $0 \mathrm{~W} / \mathrm{m}^{2}$ and remained at that minimum for $5 \mathrm{~min}$, in good agreement with the data presented by Maturilli and Ritter [17]. It should be noted that when measuring small values of solar irradiance, the accuracy of the instrumentation must be taken into account. The Kipp and Zonen CMP10 pyranometer has a directional response of $<10 \mathrm{~W} / \mathrm{m}^{2}$, Zero Offset A of $<7 \mathrm{~W} / \mathrm{m}^{2}$, and Zero Offset B of $<2 \mathrm{~W} / \mathrm{m}^{2}$. The temperature of the instrument varies proportionally to the ambient temperature and may cause thermal currents within the enclosure which is addressed by Zero Offset B. Zero Offset B is quantified in ISO 9060:1990 as the response, in $\mathrm{W} / \mathrm{m}^{2}$, to a $5 \mathrm{~K} / \mathrm{h}$ change in the ambient temperature. However, during an eclipse the ambient temperature changes at a much higher rate than $5 \mathrm{~K} / \mathrm{h}$. Similarly, as the ambient temperature is changing so is the temperature difference between the detector's "view" and the instrument housing. This is quantified by Zero Offset A. Although, in this instance the presence of the CVF4 ventilation unit should help minimize Zero Offset A. Thus, while the diffuse horizontal irradiance did reach a value of $0 \mathrm{~W} / \mathrm{m}^{2}$ before totality and remained briefly at that value after totality, this does not necessarily indicate that this is a physical characteristic of a solar eclipse. Rather, this observation could largely be attributed to the measurement device itself. Between the start of partial eclipse and maximum eclipse, the DHI decreased at a rate of $6.70 \mathrm{~W} /$ $\mathrm{m}^{2} / \mathrm{min}$. By the end of partial eclipse at 16:08 LST, the DHI had increased to a value of $249.0 \mathrm{~W} / \mathrm{m}^{2}$. Between maximum eclipse and the end of partial eclipse, the DHI increased at 
a rate of $2.96 \mathrm{~W} / \mathrm{m}^{2} / \mathrm{min}$. The rate of decrease in the DHI before totality is greater than the increase in the DHI after totality due to normal diurnal variations of solar irradiance during the afternoon.

\section{Global horizontal irradiance}

The global horizontal irradiance (GHI) was measured by an unshaded pyranometer (Kipp \& Zonen CMP10). The global horizontal irradiance 2 days prior to the eclipse (19 August 2017) and on the day of the eclipse (21 August 2017) can be seen in Figs. 9 and 10, respectively. On 19 August 2017, the GHI reached a maximum value of $1038 \mathrm{~W} / \mathrm{m}^{2}$ at 12:13 LST. It should be noted, however, that this maximum was recorded in a period of intermittent cloud coverage. If the data obtained during the transitory cloud coverage are neglected, one would note that the maximum would occur near solar noon (13:27 LST) as expected. Similarly, on the day of the solar eclipse (21 August 2017), a maximum value was also recorded near solar noon. Between the start of partial eclipse and maximum eclipse, the GHI reached a maximum value of $1138 \mathrm{~W} / \mathrm{m}^{2}$ at 13:29 LST ( 2 min after solar noon). At the time of maximum eclipse (14:44), the GHI was measured to be $1.68 \mathrm{~W} / \mathrm{m}^{2}$. The GHI reached a minimum value of $1.54 \mathrm{~W} / \mathrm{m}^{2} 1 \mathrm{~min}$ after totality. A minute later, the GHI was measured to be $1.97 \mathrm{~W} / \mathrm{m}^{2}$ and increased thereafter. Thus, the GHI dropped below a value of $2.0 \mathrm{~W} /$ $\mathrm{m}^{2}$ for $3 \mathrm{~min}$. For reference, the point of greatest eclipse experienced $2 \mathrm{~min}$ and $40.1 \mathrm{~s}$ of totality while the point of greatest duration experienced totality for $2 \mathrm{~min}$ and $40.2 \mathrm{~s}$. By the end of partial eclipse, the GHI had increased to a value of $272.3 \mathrm{~W} / \mathrm{m}^{2}$. As with the direct normal irradiance and diffuse horizontal irradiance, the rate of decrease in the global horizontal irradiance between the start of partial eclipse and maximum eclipse was greater than the rate of

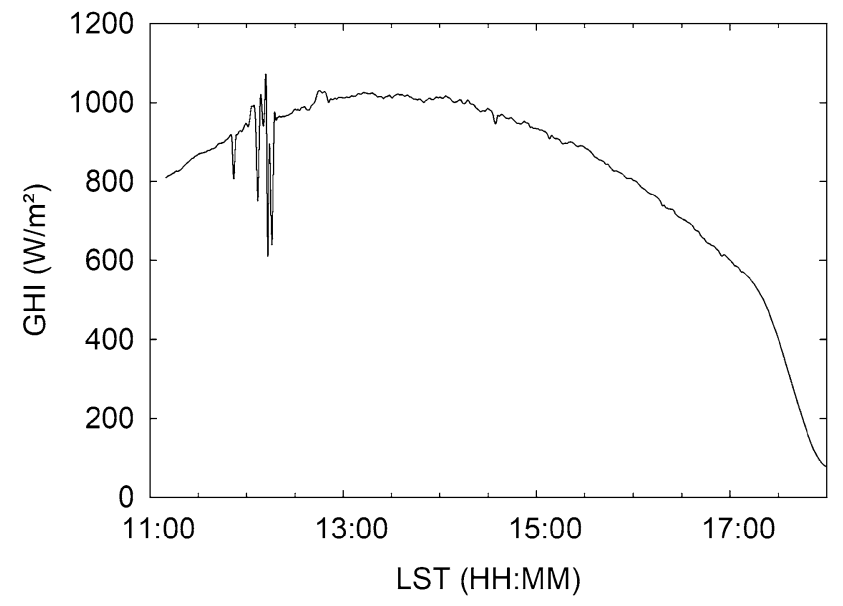

Fig. 9 Global horizontal irradiance as a function of time on 19 August 2017

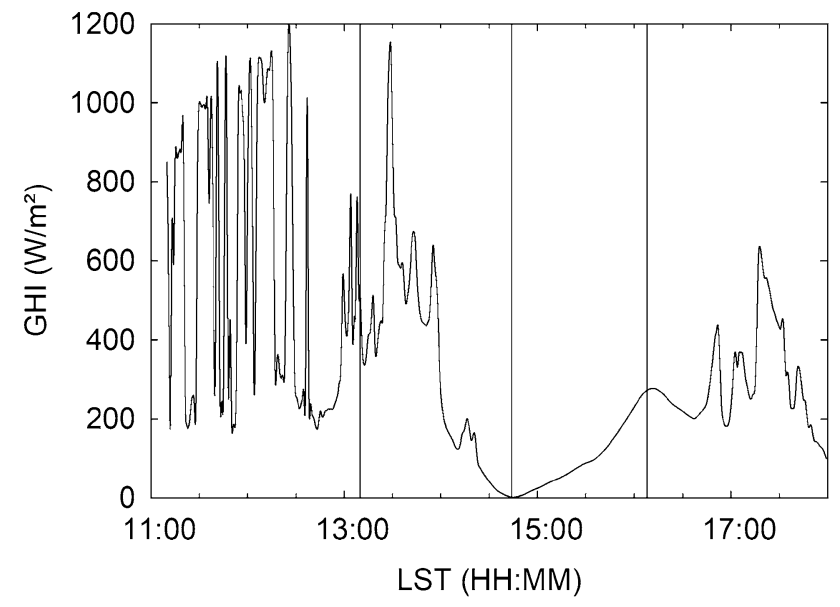

Fig. 10 Global horizontal irradiance as a function of time on 21 August 2017

increase between maximum eclipse and the end of partial eclipse. Between the start of partial eclipse and maximum eclipse, the GHI decreased at a rate of $14.95 \mathrm{~W} / \mathrm{m}^{2} / \mathrm{min}$. Between maximum eclipse and the end of partial eclipse, the GHI increased at a rate of $3.26 \mathrm{~W} / \mathrm{m}^{2} / \mathrm{min}$. It should be reiterated, however, that as the global horizontal irradiance consists of both direct and diffuse components, the intermittent cloud coverage observed during the measurement period may impact the magnitude of these rates.

\section{Summary of temperature and irradiance data}

For convenience, an overview of the temperature and solar irradiance data previously presented can be found in Tables 2 and 3. It should be noted that the change in time presented in Table 2 corresponds to the duration of time after totality at which the minimum temperature was reached.

The purpose of Table 3 is to highlight the differences in the direct normal, diffuse horizontal, and global horizontal irradiances on the day of the eclipse and 2 days prior to the eclipse when the weather conditions were near-ideal. The maximum diffuse horizontal irradiance 2 days prior to the eclipse was $201.0 \mathrm{~W} / \mathrm{m}^{2}$ while the maximum diffuse horizontal irradiance on the day of the eclipse was $495.9 \mathrm{~W} / \mathrm{m}^{2}$. The discrepancy can be attributed to the fact that there was almost zero cloud coverage during the observation window on 19 August 2017. However, on the day of the eclipse there

Table 2 Maximum and minimum temperatures on 21 August 2017

\begin{tabular}{lllll}
\hline & $T_{\max }\left({ }^{\circ} \mathrm{C}\right)$ & $T_{\min }\left({ }^{\circ} \mathrm{C}\right)$ & $\Delta T\left({ }^{\circ} \mathrm{C}\right)$ & $\Delta t$ (MM:SS) \\
\hline CHP1 & 34.03 & 25.86 & 8.17 & $43: 53.5$ \\
CGR4 & 34.59 & 25.79 & 8.80 & $50: 53.5$ \\
TBR & 31.7 & 26.7 & 5.0 & \\
\hline
\end{tabular}


Table 3 Direct, diffuse, and global solar irradiance on 19 August 2017 and 21 August 2017

\begin{tabular}{|c|c|c|c|c|c|c|c|c|}
\hline & \multicolumn{4}{|c|}{19 August 2017} & \multicolumn{4}{|c|}{21 August 2017} \\
\hline & Max & LST (HH:MM) & Min & LST (HH:MM) & $\operatorname{Max}$ & LST (HH:MM) & Min & LST (HH:MM) \\
\hline $\mathrm{DNI}\left(\mathrm{W} / \mathrm{m}^{2}\right)$ & 925.0 & 14:04 & 404.9 & $12: 13$ & 869.0 & 12:08 & 0.0 & $14: 24$ \\
\hline $\mathrm{DHI}\left(\mathrm{W} / \mathrm{m}^{2}\right)$ & 201.0 & $12: 13$ & 63.2 & 18:08 & 495.9 & $13: 30$ & 0.0 & $14: 43$ \\
\hline $\mathrm{GHI}\left(\mathrm{W} / \mathrm{m}^{2}\right)$ & 1038.0 & $12: 12$ & 67.5 & 18:08 & 1138.0 & $13: 29$ & 1.5 & $14: 45$ \\
\hline
\end{tabular}

was intermittent cloud coverage throughout the observation window. Thus, there was more scattering of the solar irradiance in the atmosphere due to the presence of clouds. Similarly, one may find it abnormal that the minimum direct normal irradiance $\left(404.9 \mathrm{~W} / \mathrm{m}^{2}\right)$ on 19 August 2017 occurred at 12:13 LST (approximately, 74 min before solar noon) when the direct normal irradiance should still be rising due to normal diurnal trends. However, the drop in the direct normal irradiance can be attributed entirely to the brief presence of cloud coverage at that time (see Fig. 5). Two days prior to the eclipse, the diffuse horizontal and global horizontal irradiances reached a minimum at the end of the observation window as expected. Though outside of the observation window reported, these irradiances would continue to decrease until shortly after sunset. As expected, on the day of the eclipse (21 August 2017) the diffuse horizontal and global horizontal irradiances reached a maximum value near solar noon which occurred at 13:27 LST. In a similar manner, the diffuse horizontal and global horizontal irradiances reached a minimum near totality which occurred at 14:44 LST.

\section{Conclusions}

The direct and diffuse components of near-surface solar irradiance, as well as the temperature of the surrounding air, were quantified during the total solar eclipse on 21 August 2017. Data from the same observation window, 2 days prior to the eclipse when the weather conditions were near-ideal, were also presented for comparison. Thermistors contained within a pyrheliometer and pyrgeometer recorded temperature drops of 8.17 and $8.80{ }^{\circ} \mathrm{C}$, respectively. The lowest temperatures measured by the pyrheliometer and pyrgeometer were recorded approximately 44 and $51 \mathrm{~min}$ after totality. The longer than expected temperature lag was attributed to the location of the thermistors within the instruments' enclosures. The temperature decreased at an average rate of $0.091{ }^{\circ} \mathrm{C} / \mathrm{min}$ between first contact and the minimum temperature occurrence. The temperature increased at an average rate of $0.032^{\circ} \mathrm{C} / \mathrm{min}$ between the minimum temperature occurrence and fourth contact. The difference in the magnitude of the temperature gradients can be largely attributed to normal diurnal variations in the temperature of the air as the solar eclipse occurred in the afternoon (maximum eclipse occurred at 14:44 LST). Unfortunately, on the day of the solar eclipse cloud coverage impeded the ability of the authors to ascertain any qualitative trends in the direct normal irradiance. However, temporal variations in the diffuse (and thus global) horizontal irradiance could be characterized. Between the start of partial eclipse and maximum eclipse, the diffuse horizontal irradiance decreased at a rate of $6.70 \mathrm{~W} / \mathrm{m}^{2} / \mathrm{min}$. Between maximum eclipse and the end of partial eclipse, the diffuse horizontal irradiance increased at a rate of $2.96 \mathrm{~W} / \mathrm{m}^{2} / \mathrm{min}$. As with the ambient temperature, the rate of decrease in the diffuse horizontal irradiance before totality was greater than the rate of increase in the DHI after totality. Thus, the total occultation of the sun by the moon markedly impacted both the temperature of the atmosphere as well as the quantity of solar irradiance reaching the surface. These well-documented changes, in addition to other meteorological parameters such as relative humidity, wind speed, and wind direction, could be used to further model the dynamic response of the atmosphere to rapid changes in solar irradiance. In addition, the data provided could be used by researchers to quantify additional items of interest such as aerosol optical depth and total column ozone.

Acknowledgements The authors would like to thank Georgia Power Company for their support via the Georgia Research for Academic Partnership in Engineering (GRAPE) Program (Grant Number: 39G6337). Any opinions, findings, and conclusions or recommendations expressed in this material are those of the authors and do not necessarily reflect the views of Georgia Power Company. In addition, the authors would like to thank the Center for Sustainability at Georgia Southern University for their support via a Sustainability Fee Project Award which exemplifies Student Sustainability Fees at Work. Finally, the authors would like to thank Brandon Kimmons, Director of Computational Research Technical Support, at Georgia Southern University for his assistance with remote data collection capabilities.

Data Availability The datasets during and/or analyzed during the current study are available from the corresponding author on reasonable request.

\section{Compliance with ethical standards}

Conflicts of interest The authors declare that they have no conflict of interest. 
Open Access This article is distributed under the terms of the Creative Commons Attribution 4.0 International License (http://creativeco mmons.org/licenses/by/4.0/), which permits unrestricted use, distribution, and reproduction in any medium, provided you give appropriate credit to the original author(s) and the source, provide a link to the Creative Commons license, and indicate if changes were made.

\section{References}

1. Fernandez, W., Castro, V., Wright, J., Hidalgo, H., Saenz, A.: Changes in solar irradiance and atmospheric turbidity in costa rica during the total solar eclipse of July 11, 1991. Earth Moon Planet. 63, 119-132 (1993)

2. Iqbal, M.: An Introduction to Solar Radiation, p. 49. Academic Press Canada, Ontario (1983)

3. Fernandez, W., Hidalgo, H., Coronel, G., Morales, E.: Changes in meteorological variables in Coronel Oviedo, Paraguay, during the total solar eclipse of 3 November 1994. Earth Moon Planet. 74, 49-59 (1996)

4. Zerefos, C.S., Balis, D.S., Zanis, P., Meleti, C., Bais, A.F., Tourpali, K., Melas, D., Ziomas, I., Galani, E., Kourtidis, K., Papayannis, A., Gogosheva, Z.: Changes in surface UV solar irradiance and ozone over the balkans during the eclipse of August 11, 1999. Adv. Space Res. 27(12), 1955-1963 (2001)

5. Blumthaler, M., Bais, A., Webb, A., Kazadzis, S., Kift, R., Kouremeti, N., Schallhart, B., Kazantzidis, A.: Variations of solar radiation at the earth's surface during the total solar eclipse of 29 March 2006. In: Remote Sensing of Clouds and the Atmosphere XI, Stockholm (2006)

6. Kazadzis, S., Bais, A., Blumthaler, M., Webb, A., Kouremeti, N., Kift, R., Schallhart, B., Kazantzidis, A.: Effects of total solar eclipse of 29 March 2006 on surface radiation. Atmos. Chem. Phys. 7, 5775-5783 (2007)

7. Kazantzidis, A., Bais, A.F., Emde, C., Kazadzis, S., Zerefos, C.S. Attenuation of global ultraviolet and visible irradiance over greece during the total solar eclipse of 29 March 2006. Atmos. Chem. Phys. 7, 5959-5969 (2007)
8. Phillips, K.J.: Air temperature variations during a recent solar eclipse. J. Br. Astron. Assoc. 79, 460-466 (1969)

9. Fernandez, W., Castro, V., Hidalgo, H.: Air temperature and wind changes in Costa Rica during the total solar eclipse of July 11, 1991. Earth Moon Planet. 63(2), 133-147 (1993)

10. Anderson, J.: Meteorological changes during a solar eclipse. Weather 54, 207-215 (1999). https://doi. org/10.1002/j.1477-8696.1999.tb06465.x

11. Peñaloza-Murillo, M.A., Pasachoff, J.M.: Air-cooling mathematical analysis as inferred from the air-temperature observation during the 1st total occultation of the sun of the 1st century at Lusaka, Zambia. J. Atmos. Solar Terr. Phys. 125-126, 59-77 (2015)

12. Grobner, J., Kazadzis, S., Kouremeti, N., Doppler, L., Tagirov, R., Shapiro, A.: Spectral solar variations during the eclipse of March 20th, 2015 at two european sites. In: AIP Conference Proceedings (2017)

13. Koepke, P., Reuder, J., Schween, J.: Spectral variation of the solar radiation during an eclipse. Meteorol. Z. 10(3), 179-186 (2001)

14. Krezhova, D.D., Krumov, A.H., Yanev, T.K.: Spectral investigations of the solar radiation during the total solar eclipse on March 29, 2006. J. Atmos. Solar Terr. Phys. 70, 365-370 (2008)

15. Dani, K.K., Devara, P.C.: Aerosol optical depth and ozone variations during the total solar eclipse of 24 October 1995. Atmos. Res. 65, 1-15 (2002)

16. Winkler, P., Kaminski, U., Kohler, U., Riedl, J., Schroers, H., Anwender, D.: Development of meteorological parameters and total ozone during the total solar eclipse of August 11, 1999. Meteorol. Z. 10(3), 193-199 (2001)

17. Maturilli, M., Ritter, C.: Surface radiation during the total solar eclipse over Ny-Alesund, Svalbard, on 20 March 2015. Earth Syst. Sci. Data 8, 159-164 (2016)

Publisher's Note Springer Nature remains neutral with regard to jurisdictional claims in published maps and institutional affiliations. 